\section{A COCHIN-CHINA REMEDY FOR LEPROSY}

A NOTE in NATURE (vol. xxi. p. I9) refers to a remedy for leprosy, obtained from Cochin-China, but the origin of which is inperfectly known. Its name is given as hruang-nao. In Mr. Consul Tremlett's Report (For. Off. Repts. No. 2I, p. 1237) it appears as hoang-nau. We have taken a good deal of trouble about this drug at Kew, and the inclosed extract from the Kew Report for I877, p. 3r, contains all that has been positively ascertained about it at present :-

"Hoâng"nan, a Supposed Remedy for Leprosy.-Mr. Prestoe, Superintendent of the Trinidad Botanic Garden, has drawn my attention to some accounts given in Les Missions Catholiques for 1875 , describing the surprising efficacy of a drug, the produce of a plant found in CochinChina, in the treatment of leprosy and rabies. The plant is known by the name of Hoâng-nan, and the description, which is of the vaguest kind, represents it as a climber, and its bark as the efficacious portion.

"M. L. Pierre, the Director of the Botanic Garden at Saigon, has obtained an imperfect specimen of the Hoâng-nan, and informs me that he identifies it as a new species of Strychnos, which he has named $S$. gautheriana, in honour of the ecclesiastic who first gave the virtues of the Hoâng-nan a wider publicity.

"M. Pierre adds some remarks which appear to me worthy of placing on record:-'The bark of Strychnos nux-vomica is regarded in Cambodia and Siam as a poison no less certain than that extracted from the seeds. The natives have remarked the fact, which is also believed to hold good in the case of cinchonas, that the bark has the most powerful properties when it has been covered with moss or otherwise protected from the action of light.' In collecting the bark great attention is paid in consequence to the circumstances under which it has been produced." W. T. THISELTON DYER

\section{SOME POINTS IN THE HISTORY OF SPECTRUM ANALYSIS}

A PHYSICAL problem begins like a rivulet. At its first introduction it is small and seemingly unimportant-constantly however, as it winds along it receives accessions from various quarters until at length it becomes a mighty river that is finally merged in the unfathomable ocean. This course is followed by all such problems. Each begins small-grows broader and will finally bear us on to the unknown if we trust ourselves to its guidance.

I need hardly remind you that the demonstration of the decomposition of white light was one of the triumphs of the illustrious Newton. But like other problems it had its small beginning. We find in one of the earliest memoirs of the Royal Society, a paper on "The Genuine Method of Examining the Theory of Light and Colours," by Mr. Newton. Here he asks amongst others, the following questions:-

(I) Whether rays that are alike incident on the same medium, have unequal refractions?

(2) Whether rays endued with particular degrees of refrangibility, when by any means separated, have particular colours constantly belonging to them, viz., the least refrangible scarlet, the most refrangible deep violet, the middle sea green; and others other colours?

(3) Whether colours by coalescing do really change one another to produce a new colour, or produce it by mixing only?

(4) Whether a due mixture of rays, endued with all variety of colours, produces light perfectly like that of the sun? and he ends by remarking that the most proper and direct way to a conclusion is to determine such queries by

Being an address delivered by Dr. B. Stewart, F.R.S., at the opening of the present session, to the Natural Philosophy Classes at Owers College. experiment. Then follow some objections to the theory of light and colour, by the Rev. F. Pardies and Mr. Newton's reply to these objections. Into the nature of these however, it is not my purpose to enter. Let me rather adopt Newton's suggestion and bring the experiment itself before you.

You are all, no doubt, familiar with the operations of the photographer, and as a matter of fact you know that when the light from a natural object is made to pass through his lens an image of this object is impressed upon the sensitive plate placed at the focus at the other side of the lens.

If the natural object be a friend's face you obtain his photograph, if it be a tree, you get the image of the tree, if it should be a bright slit of light or a bright wire you would get the image of the slit of light or of the wire. Now here we have a slit which is rendered luminous by an intense light thrown upon it, and if we place a photographer's lens before it we shall obtain an image of the slit. You see the image thrown upon a screen and you see moreover that the light is white ; it is in fact the electric light which illumines the slit. For the machine by which this light is produced our college is indebted to the generosity of Mr. Wilde. But my object is not now to discuss the electric light, but to show you that it is white and like the light of the sun-since, as you see, its image on the screen is white. Let us now interpose a prism or train of prisms between the lens and the screen. These prisms will do two things. In the first place they will bend the rays towards the base or thick part of the prisms so that in order to catch the image the screen must be moved in this direction. But in the second place they will bend some rays more than others ;-if the slit be lighted by pure red light it will be least bent, if by orange, this will be more bent than the red, if by yellow this will be more bent than the orange, then follow green, blue, indigo, and violet, the latter of which is most bent.

Now if the light behind the slit be a mixture of red, orange, yellow, green, blue, indigo, violet, we shall have a series of images of the slit overlapping one another, and forming a long ribbon of light of which the portion least bent will be coloured red and that which is most bent will be violet. Let us now see what we get from the light we are using. Here you see we have all the colours of the rainbow, red, orange, yellow, green, blue, indigo, violet, and therefore our light must contain all these; but our light was white like that of the sun and thus you see we are entitled to say that white light is composed of a mixture of these various colours.

In fact what we have done by the prism has been to separate these various constituent rays from one another and throw one on one part of the screen and the other on another part. But now if we make these various constituents to dance so quickly before our eyes that we get a united impression of the whole, we shall imagine once more that we have white light. We separated the rays in space-let us now combine them in time-and you see the thing is white. We have thus demonstrated the composition of white light after the way by which the chenist proves the composition of water, first decomposing it by the battery into oxygen and hydrogen, and then causing these two gases once more to recombine. I will now remind you that light consists of waves or undulations given out by the luminous body. These waves take place in a medium called ether, surrounding us all, in which they proceed with incredible swiftness. The light given out by a luminous particle may thus be compared to the note or notes given out by a bell. In solids and liquids however the particles are so closely packed together that they may be likened to a number of different bells all tied together in such a way that the total mass is capable of giving out every, or almost every, variety of note. From an incandescent solid or liquid body, when sufficiently hot, you thus get every variety of light, and 